\title{
Tick distribution along animal tracks: implication for preventative medicine
}

\author{
Tomáš Raši ${ }^{1, A-B, F}$, Igor Majláth ${ }^{1, A-C, F}$, Michał Bogdziewicz ${ }^{2,3, C-F}, K^{2} z y s z t o f$ Dudek $^{4,5, D-F}$, \\ Viktória Majláthová',6,A-B,F, Jan Włodarek ${ }^{7, C, E-F}$, Maroš Almáši ${ }^{1, B, F}$, Blažena Vargováá, ${ }^{6, F}$, \\ Piotr Tryjanowski ${ }^{4, A, D-F}$ \\ ${ }^{1}$ Pavol Jozef Safarik University, Kosice, Slovak Republic \\ ${ }^{2}$ Department of Systematic Zoology, Faculty of Biology, Adam Mickiewicz University, Poznań, Poland \\ ${ }^{3}$ CREAF, Cerdanyola del Valles, Catalonia, Spain \\ ${ }^{4}$ Institute of Zoology, Poznań University of Life Sciences, Poznań, Poland \\ ${ }^{5}$ Research \& Development Centre, HiProMine S.A., Robakowo, Poland \\ ${ }^{6}$ Institute of Parasitology, Slovak Academy of Sciences, Kosice, Slovak Republic \\ ${ }^{7}$ Department of preclinical sciences and infectious diseases, Poznań University of Life Sciences, Poznań, Poland \\ A - Research concept and design, B - Collection and/or assembly of data, C - Data analysis and interpretation, \\ $D$ - Writing the article, E - Critical revision of the article, F - Final approval of article
}

Raši T, Majláth I, Bogdziewicz M, Dudek K, Majláthová V, Włodarek J, Almáši M, Vargová B, Tryjanowski P. Tick distribution along animal tracks: implication for preventative medicine. Ann Agric Environ Med. 2018; 252): 360-363. doi: 10.26444/aaem/89919

\begin{abstract}
Introduction. Tick abundance and the prevalence of the pathogens they carry have been increasing worldwide in the last decades, and is projected to increase even further. Despite the fact that problem is global, there still remain many gaps in the diagnosis and treatment of tick-borne diseases. The best protection from tick-borne pathogens, therefore, is prevention and avoidance of bites. Ticks mobility is limited so that their spatial distribution is strongly correlated with the presence of, especially with large mammals. In this study, the hypothesis was tested that tick abundance is higher on animal tracks in the forests than in adjacent habitats. This is an important issue because there are still several human habits and practices that can decrease the zoonoses risk. For example, during recreation in forest, people should always walk on the paths (including narrow animal's tracks) instead of wading through bushes.

Materials and method. Flagging of animal trails and near control transects were performed simultaneously. Next, collected ticks were counted, sexed and aged.

Results. The abundance of ticks was almost 5-fold (Ixodes ricinus) and 3-fold (Dermacentor spp.) higher on animal trails than on adjacent control transects.

Conclusions. The results obtained support the hypothesis that ticks are more abundant on pathways than in adjacent habitats. Most likely, the pattern emerges because large mammals, like deer, which are the most important ticks hosts, use forest paths to move across the landscape and frequently move along the same routes. This research sends an important public message that these forest trails are hotspots of disease risk and should be avoided.
\end{abstract}

\section{Key words}

One Health, tick-borne diseases, spatial distribution, preventive medicine, Ixodes, human behaviour

\section{INTRODUCTION}

Ticks as pathogen vectors are major ectoparasites of humans [1] and have a crucial influence on the epidemiology of zoonoses, such as Lyme disease [2,3] and ticks-borne encephalitis [4], babesiosis [5] as well as numerous others less frequent diseases $[6,7]$. Moreover, both tick abundance and the prevalence of pathogens the ticks carry has increased worldwide in the last decades, and is projected to increase even further [8-11]. Therefore, numerous studies have explored how their abundance and associated disease risk changes in time and over large spatial scales [12-17]. However, the distribution of ticks at the microhabitat scale, in conjunction with co-use of these habitats by humans, will define the disease risk observed at the landscape scale.

The mobility of ticks is limited as nymphs are able to move only ca. $1 \mathrm{~m}$, while adults can move ca. $3.5 \mathrm{~m}[18,19]$.

Address for correspondence: Krzysztof Dudek, Institute of Zoology, Wojska Polskiego, 60-625 Poznań, Poland

e-mail: dudeekk@gmail.com

Received: 15.02.2018; accepted: 13.04.2018; first published: 17.05.2018
Therefore, their spatial distribution is strongly correlated with the presence of hosts, especially large mammals [20, 21]. This non-random distribution is used in disease risk management to reduce ticks and humans co-occurrence, e.g. by creating 'ticks free' areas around houses and schools [22]. That concept is intensively studied as a vital component of the One Health conception [23, 24], i.e. sustainable management practices to protect humans from zoonoses. Nonetheless, there are still several human habits concerning practices to decrease zoonoses risk. For example, during recreation in forests, people should always keep to the paths (including narrow animal's tracks) instead of wading through the bushes. However, since the presence of ticks is strongly shaped by their host activity, not all forest pathways may be safe, and some, in fact, may be hotspots of tick abundance at the microhabitat scale. Thus, this study tests the hypothesis that tick abundance is higher on animal tracks in the forests than in adjacent habitats. 


\section{MATERIALS AND METHOD}

Sampling was performed during the active season of ticks, March - December, in 2014-2016, at 2 geographical distant areas. The first location was situated in the High Tatras in the northern part of Slovakia (N 49.161823594, E 20.269952694), with an average altitude of $900 \mathrm{~m}$ a.s.l. The second location was situated in southern part of Slovakia, in Slovak Karst ( $\mathrm{N} 48.589756604, \mathrm{E} 20.697413282$ ), with average altitude of $200 \mathrm{~m}$ a.s.l. In both locations, 39 sites (in total) were selected for tick sampling which had evidence of the presence of an animal trail at least 100 meters long. Each trail was paired with a control transect that was parallel to the animal trail, and spaced approximately $5 \mathrm{~m}$ away. It was ensured that the control trails did not cross other animal trails, residential signs of animals, piles of droppings or noticeable resting areas of animals, and were located in the same habitats as animal trails. Tick populations were sampled by flagging questing ticks. Each flag consisted of a $1 \mathrm{~m}^{2}$ piece of white cotton flannel attached to a $1.2 \mathrm{~m}$ wooden dowel [25]. The flag pulled along the canopy cover, grassy vegetation, shrubs and leaf litter. Every $2 \mathrm{~m}$ the flag was examined for the presence of ticks, and collected if present. The flagging of animal trails and control transects were carried out simultaneously, but no samples were collected during rain or on wet vegetation. Fields workers were regularly swapped between treatments to avoid potential bias. All ticks were released back at the place of capture. Sampled ticks were identified to species level (Ixodes ricinus) or genus level (Dermacentor spp.), gender and developmental stage were determined.

Tests were carried out for the differences in abundance of ticks using zero-inflated negative binomial (ZINB), logit link, mixture models implemented via 'pscl' package $[26,27]$ in the R software [28]. Negative binomial was used, rather than Poisson error distribution, because preliminary analysis showed that the former strongly outperformed the latter in the goodness of fit (comparison of full models with different error distribution; $\triangle \mathrm{AICc}=445.47)$. Mixture models analyze the data in 2 steps, with the first one being a binomial process that estimates the probability of measuring a zero, while in the second process, counts are modeled by negative binomial model [29]. Thus, to limit the number of models fitted, the logistic part of the model was first specified, while keeping the count part constant (intercept only). A complete model was built with tick count as the response variable and following the independent factors: treatment (trail vs. off-trail), species (I. ricinus and Dermacentor spp.), developmental stage (adults vs. nymphs), and interaction term between treatment and species. The study site was included to account for nested data structure, all of which was retained in all candidate models. Next, the Akaike information criterion corrected for the small sample size (AICc) was used to specify the optimal model structure [30]. As the next step, the model that received the highest AICc support was used, and the count part of the model was specified by including different combinations of the same set of independent effects, as before, and evaluated their fit with the AICc. The model with the lowest AICc within the set was considered the best [30]. In the analysis, genders were pooled together and their summed count was treated as 'adults', because preliminary data exploration showed no differences in the spatial distribution of males and females (see Supplementary Material, Fig. 1S). The 'MuMIn' package was used for the AICc model selection process [31].

\section{RESULTS AND DISCUSSION}

During the study, 351 Ixodes ricinus and 570 Dermacentor spp. ticks were collected (Tab. 1).

The best model included the effects of treatment, tick species, developmental stage, and the interaction between treatment and species in both the logistic and binomial count par (Tab. 2a). The interaction term in the count part of the best model suggests that $I$. ricinus responded more strongly to the trial presence (Tab. 3, Fig. 1). However, the second-best model did not include the interaction term and received similar AICc support $(\triangle \mathrm{AICc}=1.13)[32]($ Tab. $2 \mathrm{~A})$.

Generally, the overall abundance of ticks was almost 5-fold (I. ricinus) and 3-fold (Dermacentor spp.) higher on animal trails then on adjacent control transects (Tab. 3, Fig. 1).

Table 1. Total number of ticks collected on animal trails and transects along animal trails

\begin{tabular}{lcccccccc}
\hline & \multicolumn{3}{c}{ lxodes ricinus } & \multicolumn{4}{c}{ Dermacentor spp. } \\
\hline & males & $\begin{array}{c}\text { fe- } \\
\text { males }\end{array}$ & nymphs & $\begin{array}{c}\text { to- } \\
\text { gether }\end{array}$ & males & $\begin{array}{c}\text { fe- } \\
\text { males }\end{array}$ & nymphs & $\begin{array}{c}\text { to- } \\
\text { gether }\end{array}$ \\
\hline $\begin{array}{l}\text { animal } \\
\text { trail }\end{array}$ & 49 & 51 & 208 & $\mathbf{3 0 8}$ & 191 & 244 & 0 & $\mathbf{4 3 5}$ \\
\hline transect & 9 & 12 & 22 & $\mathbf{4 3}$ & 80 & 55 & 0 & $\mathbf{1 3 5}$ \\
\hline
\end{tabular}

Table 2. Model selection table. A) specification of the count part of the model, b) specification of the logistic part of the model. To limit the number of models fitted we first specified the logistic part of the model, while keeping the count part constant (intercept only). Next, we defined the count part of the model. Models are ranked according to the AICc value; log Lik - log-likelihood; AICc - Akaike's information criterion adjusted for small sample size; $\triangle \mathrm{AIC}=\mathrm{AICci}-\min \mathrm{AIC}$; wi - model weight. $\times$ denotes interaction term

\begin{tabular}{|c|c|c|c|c|c|c|}
\hline Rank & Fixed effects & Df & logLik & $\mathrm{AlCc}$ & $\triangle \mathrm{AlCc}$ & wi \\
\hline \multicolumn{7}{|c|}{ logistic part of the model } \\
\hline 1 & $\begin{array}{l}\text { Site }+ \text { Treat }+ \text { Species }+ \text { Stage }+ \text { Treat } \\
\times \text { Species }\end{array}$ & 15 & -442.6 & 917.0 & 0 & 0.99 \\
\hline 2 & Site + Treat + Species + Stage & 14 & -449.3 & 928.2 & 11.16 & 0.01 \\
\hline 3 & Site + Treat + Species & 13 & -484.0 & 995.3 & 78.32 & 0 \\
\hline 4 & Site + Treat & 12 & -489.3 & 1003.7 & 86.72 & 0 \\
\hline 5 & Site & 11 & -493.8 & 1010.6 & 93.53 & 0 \\
\hline \multicolumn{7}{|c|}{ count part of the model } \\
\hline 1 & $\begin{array}{l}\text { Site }+ \text { Treat }+ \text { Species }+ \text { Stage }+ \text { Treat } \\
\times \text { Species }\end{array}$ & 27 & -399.1 & 857.7 & 0 & 0.64 \\
\hline 2 & Site + Treat + Species + Stage & 26 & -400.9 & 858.8 & 1.13 & 0.36 \\
\hline 3 & Site + Treat + Species & 25 & -413.1 & 880.8 & 23.10 & 0 \\
\hline 4 & Site + Treat & 24 & -427.7 & 907.6 & 49.95 & 0 \\
\hline 5 & Site & 23 & -435.1 & 920.2 & 62.56 & 0 \\
\hline
\end{tabular}

Table 3. Output of the count part of the model that received highest AICC support (see Table 1). Coefficients for study sites and for the logistic part of the model are omitted

\begin{tabular}{lcc}
\hline Variable & Regression coefficient & SE \\
\hline Intercept & 3.78 & 0.52 \\
\hline Trail & 0.98 & 0.33 \\
\hline Species (I. ricinus) & -2.17 & 0.41 \\
\hline Stage (Adult) & -2.02 & 0.43 \\
\hline Trail $\times$ Species (I. ricinus) & 0.98 & 0.52
\end{tabular}


Note: 'Trail' represents the difference in abundance between trails and adjacent transects for Dermacentor. 'Species' represents the difference in abundance between Dermacentor spp. I. ricinus ticks. 'Stage' represents the difference between adult and nymph abundance. The interaction term represents the difference in the effect of trail on I. ricinus abundance in comparison to Dermacentor. The coefficients represent changes in abundance expressed on a logarithmic scale.

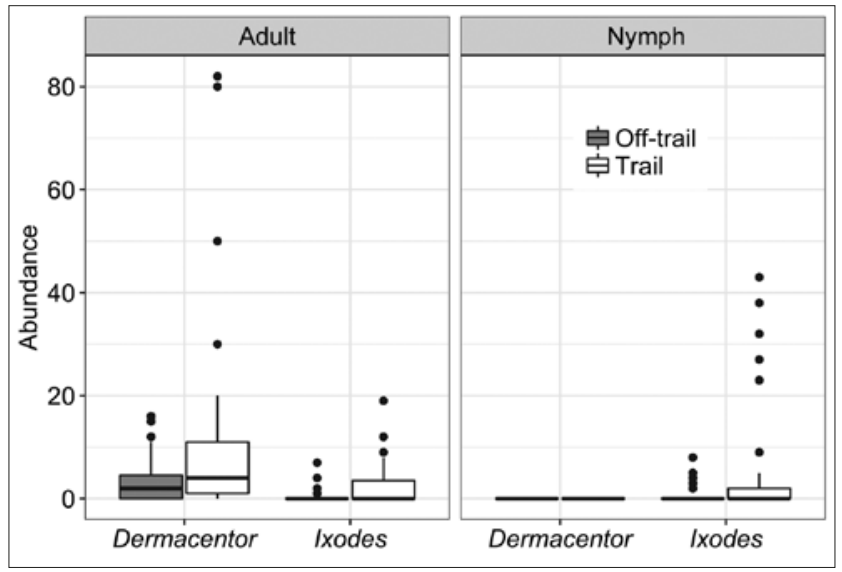

Figure 1. Spatial differences in abundance of studies ticks.

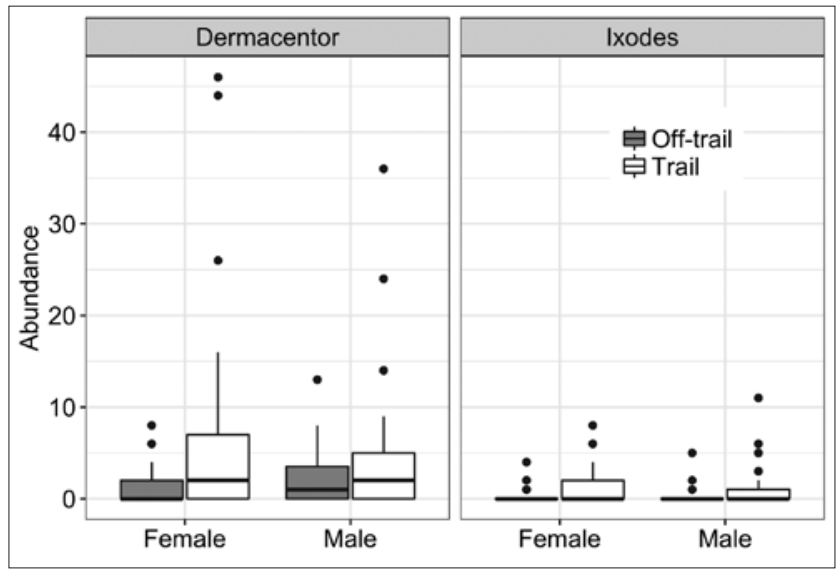

Figure 1S. Boxplots differentiating spatial distribution of tick genders

These results support the hypothesis that ticks are more abundant on pathways than in adjacent habitats. Most likely, this pattern emerges because large mammals, like deer, the most important ticks hosts, $[33,34]$, use forest paths to move across the landscape, and frequently move along the same routes [35].

Ticks leave the host after feeding by dropping on the vegetation, and molting (larvae or nymphs) or lay eggs (adult females) [36]. Since their dispersal range is very limited [18], most of them stay near the forest path, creating strong spatial differences in their abundance at the microhabitat scale. Furthermore, this study shows spatial differences in abundance among species and life stages. Lack of the Dermacentor spp. nymphs in the study sample is a consequence of the method of collection as nymphs of this species are nidicolous [37], contrary to I. ricinus nymphs [38]. One likely factor responsible for the different response of adult tick species to trail presence is different habitat preferences of the focal species. Dermacentor spp. prefer dry, open spaces, like xerophilic plant communities and open meadows, hence their occurrence within forests is generally low [39]. In contrast, I. ricinus prefers forest edges [40, 41], which likely contributes to its higher abundance on animal trails than in adjacent habitats.

\section{CONCLUSION}

The best protection from tick-borne pathogens is prevention $[23,42-44]$. One simple but very effective practice is avoidance of habitats with a heavy occurrence of ticks [45]. Numerous, recent studies have investigated how the abundance of ticks varies among habitats (e.g. forests, meadows, or city parks) [46-48], but the crucial role of the distribution of the parasites inside these habitats remains largely unexplored. The presented study aimed at filling that gap, and we disproved the popular notion that hiking on animal trails can help lower the risk of acquiring a tick. In fact, ther research sends an important public message - that these forest trails are hotspots of disease risk and should be avoided. This fact should be treated as important information for implementing preventive medical and veterinary medicine.

\section{Acknowledgements}

The study was supported by grants from the Scientific Grant Agency of the Ministry of Education of the Slovak Republic and the Slovak Academy of Sciences (VEGA 1/0417/14 (0.5)), within the project Environmental Protection Against Parasitozoonoses Under The Influence Of Global Climate And Social Changes (Code IMTS: 26220220116), supported by the Research \& Development Operational Programme funded by the ERDF; grants from the National Science Centre in Krakow, Poland - Preludium (2014/13/N/NZ8/02487) and Etiuda (2016/20/T/NZ8/00134) (K. Dudek), and Preludium (2015/17/N/NZ8/01565), Etiuda (2015/16/T/NZ8/00018), and by the Foundation for Polish Science Scholarship 'Start' (M. Bogdziewicz).

\section{REFERENCES}

1. Jongejan F, Uilenberg G. The global importance of ticks. Parasitol. 2004; 129(S1): S3-S14.

2. Burgdorfer W, Barbour AG, Hayes SF, Benach JL, Grunwaldt E, Davis JP. Lyme disease-a tick-borne spirochetosis? Science 1982; 216(4552): 1317-1319.

3. Víchová B, Horská M, Blaňarová L, Švihran M, Andersson M, Pet'ko B. First molecular identification of Babesia gibsoni in dogs from Slovakia, central Europe. Ticks and Tick-Borne Dis. 2016; 7(1): 54-59.

4. Lindquist L, Vapalahti O. Tick-borne encephalitis. The Lancet 2008; 371(9627): 1861-1871.

5. Kjemtrup A, Conrad P. Human babesiosis: an emerging tick-borne disease. Int J Parasitol. 2000; 30(12): 1323-1337.

6. Estrada-Peña A, de La Fuente J. Species interactions in occurrence data for a community of tick-transmitted pathogens. Scientific Data 2016; 3: 160056.

7. Víchová B, Majláthová V, Nováková $M$, Stanko M, Hviščová I, Pangrácová L, Chrudimský T, Čurlík J, Pet'ko B. Anaplasma infections in ticks and reservoir host from Slovakia. Infect Genet Evol. 2014; 22: 265-272.

8. Dautel H, Dippel C, Oehme R, Hartelt K, Schettler E. Evidence for an increased geographical distribution of Dermacentor reticulatus in Germany and detection of Rickettsia sp. RpA4. Int J Med Microbiol. 2006; 296: 149-156.

9. Gray J, Dautel H, Estrada-Peña A, Kahl O, Lindgren E. Effects of climate change on ticks and tick-borne diseases in Europe. Interdiscip Perspect Infect Dis. 2009; 2009: 593232. doi: 10.1155/2009/593232. Epub 2009 Jan 4. 
10. Randolph SE. To what extent has climate change contributed to the recent epidemiology of tick-borne diseases? Vet Parasitol. 2010; 167(2): 92-94.

11. Földvári G, Široký P, Szekeres S, Majoros G, Sprong H. Dermacentor reticulatus: a vector on the rise. Parasit Vectors. 2016; 9(1): 314

12. Jones CG, Ostfeld RS, Richard MP, Schauber EM, Wolff JO. Chain reactions linking acorns to gypsy moth outbreaks and Lyme disease risk. Science 1998; 279(5353): 1023-1026.

13. Randolph SE. The shifting landscape of tick-borne zoonoses: tick-borne encephalitis and Lyme borreliosis in Europe. Philos Trans R Soc Lond B Biol Sci. 2001; 356(1411): 1045-1056.

14. Estrada Peña A. The relationships between habitat topology, critical scales of connectivity and tick abundance Ixodes ricinus in a heterogeneous landscape in northern Spain. Ecography 2003; 26(5): 661-671.

15. Ostfeld RS, Canham CD, Oggenfuss K, Winchcombe RJ, Keesing F. Climate, deer, rodents, and acorns as determinants of variation in Lyme-disease risk. PLoS Biol. 2006; 4(6):e145.

16. Bogdziewicz M, Szymkowiak J. Oak acorn crop and Google search volume predict Lyme disease risk in temperate Europe. Basic Appl Ecol. 2016; 17(4): 300-307.

17. Ostfeld R. Lyme disease: the ecology of a complex system: OUP USA; 2010.

18. Gray J. A carbon dioxide trap for prolonged sampling of Ixodes ricinus L. populations. Exp Appl Acarol. 1985; 1(1): 35-44.

19. Carroll J, Schmidtmann E. Dispersal of blacklegged tick (Acari Ixodidae) nymphs and adults at the woods-pasture interface. J Med Entomol. 1996; 33(4): 554-558.

20. Ostfeld RS, Hazler KR, Cepeda OM. Temporal and spatial dynamics of Ixodes scapularis (Acari: Ixodidae) in a rural landscape. J Med Entomol. 1996; 33(1): 90-95.

21. Kugeler K, Jordan R, Schulze T, Griffith K, Mead P. Will Culling White Tailed Deer Prevent Lyme Disease? Zoonoses and Public Health 2015.

22. Pérez de León AA, Teel PD, Li A, Ponnusamy L, Roe RM. Advancing integrated tick management to mitigate burden of tick-borne diseases. Outlooks on Pest Management 2014; 25(6): 382-389.

23. Dantas-Torres F, Chomel BB, Otranto D. Ticks and tick-borne diseases: a One Health perspective. Trends Parasitol. 2012; 28(10): 437-446.

24. Rabinowitz P, Conti L. Links among human health, animal health, and ecosystem health. Ann Rev Public Health 2013; 34: 189-204.

25. Carroll J, Schmidtmann E. Tick sweep: modification of the tick dragflag method for sampling nymphs of the deer tick (Acari: Ixodidae). J Med Entomol. 1992; 29(2): 352-355.

26. Zeileis A, Kleiber C, Jackman S. Regression models for count data in R. J Stat Softw. 2008; 27(8): 1-25.

27. Jackman S. pscl: Classes and Methods for R Developed in the Political Science. R package version 1.4.9. In.: Stanford, California: Computational Laboratory, Stanford University. Department of Political Science, Stanford University. Available: http://pscl. stanford. ed u. Accessed; 2015.

28. Team RDC: R. A language and environment for statistical computing. Vienna: R Foundation for Statistical Computing;. In.; 2016.

29. Zuur A, Ieno E, Walker N, Saveliev A, Smith G. Mixed Effects Models and Extensions in Ecology with R. Springer Science+. 2009.
30. Burnham KP, Anderson DR. Model selection and multimodel inference: a practical information-theoretic approach: Springer Science \& Business Media; 2003.

31. Barton K. Multi-model inference. R package version 1.10. 0. 2014. In.; 2016.

32. Arnold TW: Uninformative parameters and model selection using Akaike's Information Criterion. J Wildl Manage. 2010; 74(6): 1175-1178.

33. Vor T, Kiffner C, Hagedorn P, Niedrig M, Rühe F. Tick burden on European roe deer (Capreolus capreolus). Exp Appl Acarol. 2010; 51(4): 405-417.

34. Wilson ML, Telford III SR, Piesman J, Spielman A. Reduced abundance of immature Ixodes dammini (Acari: Ixodidae) following elimination of deer. J Med Entomol. 1988; 25(4): 224-228.

35. Medlock J, Shuttleworth H, Copley V, Hansford K, Leach S. Woodland biodiversity management as a tool for reducing human exposure to Ixodes ricinus ticks: A preliminary study in an English woodland. J Vect Ecol. 2012; 37(2): 307-315.

36. Oliver Jr JH. Biology and systematics of ticks (Acari: Ixodida). Annu Rev Ecol Syst. 1989; 20(1): 397-430.

37. Kiewra D, Czulowska A. Evidence for an increased distribution range of Dermacentor reticulatus in south-west Poland. Exp Appl Acarol. 2013; 59(4): 501-506.

38. Vassallo M, Pichon B, Cabaret J, Figureau C, Pérez-Eid C. Methodology for sampling questing nymphs of Ixodes ricinus (Acari: Ixodidae), the principal vector of Lyme disease in Europe. J Med Entomol. 2000; 37(3): 335-339.

39. Rubel F, Brugger K, Pfeffer M, Chitimia-Dobler L, Didyk YM, Leverenz S, Dautel H, Kahl O. Geographical distribution of Dermacentor marginatus and Dermacentor reticulatus in Europe. Ticks Tick Borne Dis. 2016; 7(1): 224-233.

40. Horobik V, Keesing F, Ostfeld RS. Abundance and Borrelia burgdorferiinfection prevalence of nymphal Ixodes scapularis ticks along forestfield edges. EcoHealth 2006; 3(4): 262-268.

41. Mihalca A, Gherman C, Magdaș C, Dumitrache M, Györke A, Sándor A, Domșa C, Oltean M, Mircean V, Mărcuțan D. Ixodes ricinus is the dominant questing tick in forest habitats in Romania: the results from a countrywide dragging campaign. Exp Appl Acarol. 2012; 58(2): 175-182.

42. Due C, Fox W, Medlock JM, Pietzsch M, Logan JG. Tick bite prevention and tick removal. BMJ 2013; 347: f7123.

43. Estrada-Peña An. Forecasting habitat suitability for ticks and prevention of tick-borne diseases. Vet Parasitol. 2001; 98(1): 111-132.

44. Fish D: Environmental risk and prevention of Lyme disease. Am J Med. 1995; 98(4): 2S-9S.

45. Piesman J, Eisen L. Prevention of tick-borne diseases. Annu Rev Entomol. 2008; 53: 323-343.

46. Estrada-Peña A. Distribution, abundance, and habitat preferences of Ixodes ricinus (Acari: Ixodidae) in northern Spain. J Med Entomol. 2001; 38(3): 361-370.

47. Ginsberg HS, Ewing CP. Habitat distribution of Ixodes dammini (Acari: Ixodidae) and Lyme disease spirochetes on Fire island, New York. J Med Entomol. 1989; 26(3): 183-189.

48. Szekeres S, Lügner J, Fingerle V, Margos G, Földvári G. Prevalence of Borrelia miyamotoi and Borrelia burgdorferi sensu lato in questing ticks from a recreational coniferous forest of East Saxony, Germany. Ticks Tick Borne Dis. 2017; 8(6): 922-927. 